\title{
Perencanaan Perawatan Mesin Welding Mig Pada Produksi Sub Frame Di PT. XYZ Dengan Metode Reliability Centered Maintenance (RCM)
}

\author{
Zulkani Sinaga ${ }^{1}$, Solihin $^{2}$, Mochamad Ardan ${ }^{3}$ \\ ${ }^{1,2,3}$ Program Studi Teknik Industri, Fakultas Teknik Industri, Universitas \\ Bhayangkara Jakarta Raya, Jakarta. \\ E-mail : zulkani.sinaga@dsn.ubharajaya.ac.id, solihin@dsn.ubharajaya.ac.id
}

Artkel Info - : Received : 12 Feb 2021; Revised : 17 Feb 2021; Accepted: 27 Feb 2021

\begin{abstract}
Pemeliharaan merupakan suatu proses yang dilakukan untuk menjaga keandalan, ketersediaan dan sifat mampu merawat komponen atau mesin. Program pemeliharaan yang efektif dan efisien akan mendukung peningkatan produktifitas sistem produksi. PT. XYZ merupakan perusahaan nasional bergerak dibidang karoseri truck mengalami penurunan produktivitas disebabkan belum adanya strategi perawatan khususnya mesin welding jenis MIG sehingga sering terjadi downtime mesin mengakibatkan proses produksi menjadi terhambat. Berdasarkan alasan tersebut dibutuhkan program pemeliharaan yang efektif dan efisien dengan menerapkan analisis menggunakan metode Reliability Centered Maintenance (RCM) guna menciptakan metode pemeliharaan yang akurat, fokus, dan optimal dengan tujuan mencapai keandalan yang optimal. Penelitian dilakukan dengan mengikuti langkah-langkah perhitungan berdasarkan Failure Mode and Effect Analysis (FMEA) dan penetapan strategi pemeliharaan dengan dibantu menggunakan software minitab 18. Hasil penelitian diperoleh Risk Priority Number (RPN) untuk komponen wire feeder sebesar 611, dengan pola distribusi waktu normal, nilai parameter median 61,9391 dan standar deviasinya 48,6053, nilai Mean Time To Failure (MTTF) sebesar 61,9391 jam dan selang interval waktu penggantian komponen sebesar 10,1349. Berdasarkan hasil perhitungan performance maintenanace diketahui nilai Mean Time Between Failure (MTBF) antara 31,92 72,09 jam, Mean Time To Repair (MTTR) anatara 1,19 1,78 jam dan availability antara 94,67\% 98,24\%, setelah dilakukan tindakan perawatan pencegahan selama periode tersebut dihasilkan nilai availability sebesar 98,01\% artinya kerusakan pada komponen wire feeder dapat teratasi
\end{abstract}

Kata kunci: Downtime, Mesin Welding, RCM, FMEA, Strategi Pemeliharaan

Abstract
Maintenance is a process carried out to maintain reliability, availability and the nature of being able to care for components or machines. An effective and efficient maintenance program will support increased productivity of the production system. PT. XYZ is a national company engaged in the truck body which has decreased productivity due to the absence of a maintenance strategy, especially MIG welding machines, so that machine downtime often occurs which results in the production process being hampered. Based on these reasons, an effective and efficient maintenance program is needed by applying analysis using the Reliability Centered Maintenance (RCM) method in order to create an accurate, focused and optimal maintenance method with the aim of achieving optimal reliability. The research was carried out by following the calculation steps based on Failure Mode and Effect Analysis (FMEA) and the determination of the maintenance strategy assisted by using Minitab 18 software. The research results obtained a Risk Priority Number (RPN) for the wire feeder component of 611, with a normal time distribution pattern, the median parameter value is 61.9391 and the standard deviation is 48.6053, the Mean Time To Failure $(M T T F)$ value is 61.9391 hours and the component replacement time interval is 10.1349. Based on the results of performance maintenance calculations, it is known that the Mean Time Between Failure $(M T B F)$ value is between $31.92 \sim 72.09$ hours, the Mean Time To Repair (MTTR) is between $1.19 \sim 1.78$ hours and the availability is between $94.67 \% \sim 98,24 \%$, after taking preventive maintenance measures during that period the resulting availability value was $98.01 \%$, meaning that the damage to the wire feeder components could be resolved.

Keywords: Downtime, Welding Machine, RCM, FMEA, Maintenance Strategy 


\section{PENDAHULUAN}

PT. XYZ merupakan perusahaan nasional yang bergerak di bidang produksi karoseri khususnya untuk jenis karoseri truck. Dalam menjalankan bisnisnya PT. XYZ fokus pada produksi pembuatan kendaraan Crane dan Dump Truck, besarnya permintaan pelanggan untuk produk sub frame mengharuskan perusahaan untuk menyerap teknologi tinggi dan menerapkannya secara konsisten sehingga menghasilkan produk unggulan , produk ini diproduksi melalui beberapa tahapan dengan mengandalkan mesin-mesin seperti Cutting Plate, Bending Plate, Welding,dan Metal Inert Gas (MIG). Adanya kerusakan pada salah satu mesin dapat menyebabkan kendala besar bagi perusahaan, permasalahan yang dihadapi perusahaan saat ini terjadi kerusakan pada mesin welding, sehingga terdapat downtime mesin yang cukup besar disebabkan belum adanya strategi pemeliharaan yang mampu mengatasi permasalahan tersebut. Mengingat pentingnya peranan mesin Welding MIG untuk menjamin kelancaran produksi sub frame, maka pemeliharaan mesin tersebut harus menjadi perhatian bagi perusahaan agar peluang terjadinya downtime akibat kerusakan mesin dapat diminimalkan. Data kerusakan mesin welding pada periode November 2019 April 2020 sebagai berikut ;

Tabel 1.1 Laporan Data Kerusakan Mesin Welding (Nov 2019 - April 2020 )

\begin{tabular}{|c|c|c|c|c|}
\hline \multirow[b]{2}{*}{ Bulan } & \multirow{2}{*}{$\begin{array}{c}\text { Frekuensi } \\
\text { Breakdown }\end{array}$} & \multicolumn{2}{|c|}{ Total Operation Time } & \multirow{2}{*}{$\begin{array}{l}\text { Total } \\
\text { (jam) }\end{array}$} \\
\hline & & $\begin{array}{c}\text { Loading } \\
\text { (Operation) }\end{array}$ & $\begin{array}{l}\text { Breakdown } \\
\text { (TTR) }\end{array}$ & \\
\hline November & 7 & 390 & 9.30 & 380.30 \\
\hline Desember & 12 & 570 & 14.25 & 555.35 \\
\hline Januari & 9 & 660 & 11.20 & 648.40 \\
\hline Februari & 10 & 570 & 14.05 & 555.55 \\
\hline Maret & 9 & 630 & 14.25 & 615.35 \\
\hline April & 8 & 270 & 14.25 & 255.35 \\
\hline
\end{tabular}

Sumber ; PT. XXX (2020)

Tabel 1.2 Jumlah Kerusakan Komponen (Nov 2019 - April 2020 )

\begin{tabular}{lcccccccc}
\hline No & Komponen & Nov & Des & Jan & Feb & Maret & April & Total \\
\hline 1. & Gun & 3 & 4 & 1 & 3 & 0 & 0 & $\mathbf{1 1}$ \\
\hline 2. & Wire Feeder & 3 & 3 & 6 & 2 & 5 & 5 & $\mathbf{2 4}$ \\
\hline 3. & Selang Regulator & 1 & 3 & 0 & 1 & 1 & 0 & $\mathbf{6}$ \\
\hline 4. & Trafo & 0 & 1 & 1 & 1 & 2 & 2 & $\mathbf{7}$ \\
\hline 5. & Stop Kontak & 0 & 1 & 1 & 3 & 1 & 1 & $\mathbf{7}$ \\
\hline & Total Frekuensi & $\mathbf{7}$ & $\mathbf{1 2}$ & $\mathbf{9}$ & $\mathbf{1 0}$ & $\mathbf{9}$ & $\mathbf{8}$ & $\mathbf{5 5}$ \\
\hline Sur
\end{tabular}

Sumber; PT. XXX (2020)

Dari tabel komponen diatas dapat dilihat tingkat kerusakan mesin welding terjadi pada komponen Wire feeder yang masih tinggi dengan nilai downtime terlama yaitu 24 jam. 


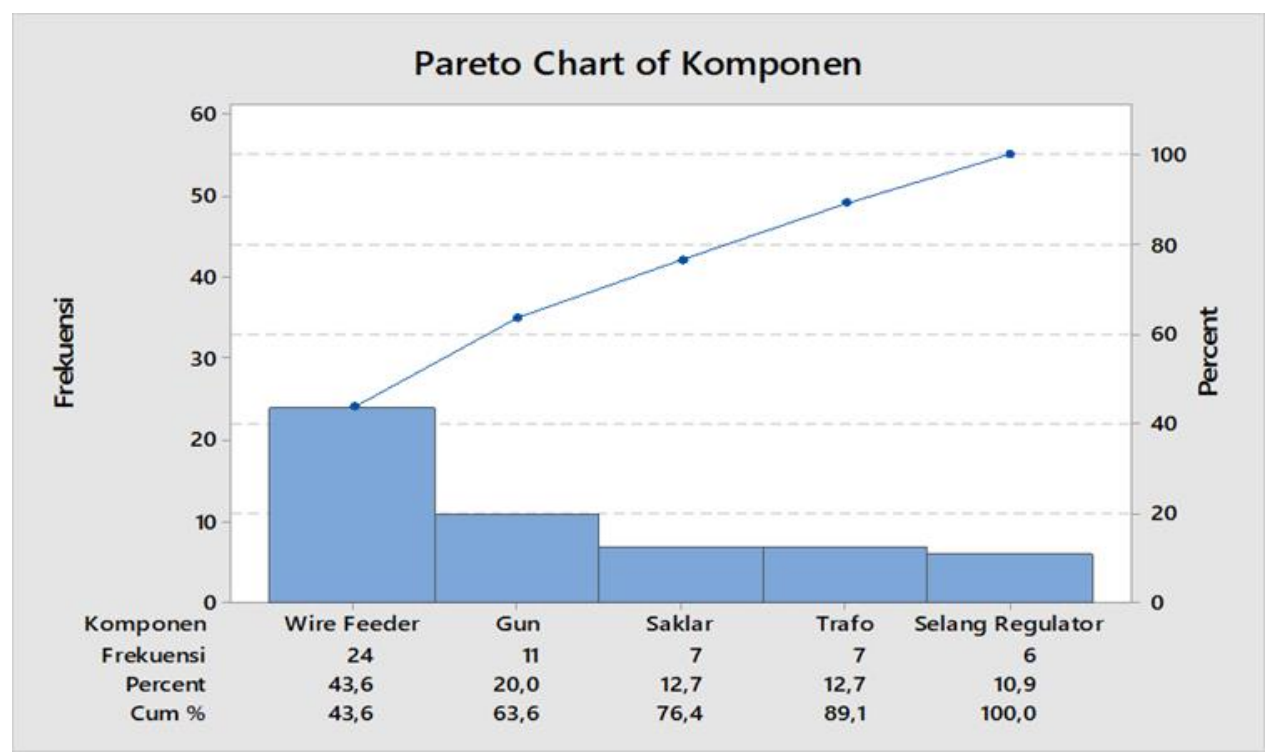

Gambar 1.1. Grafik Komponen Periode ( Nov 2019 - April 2020 )

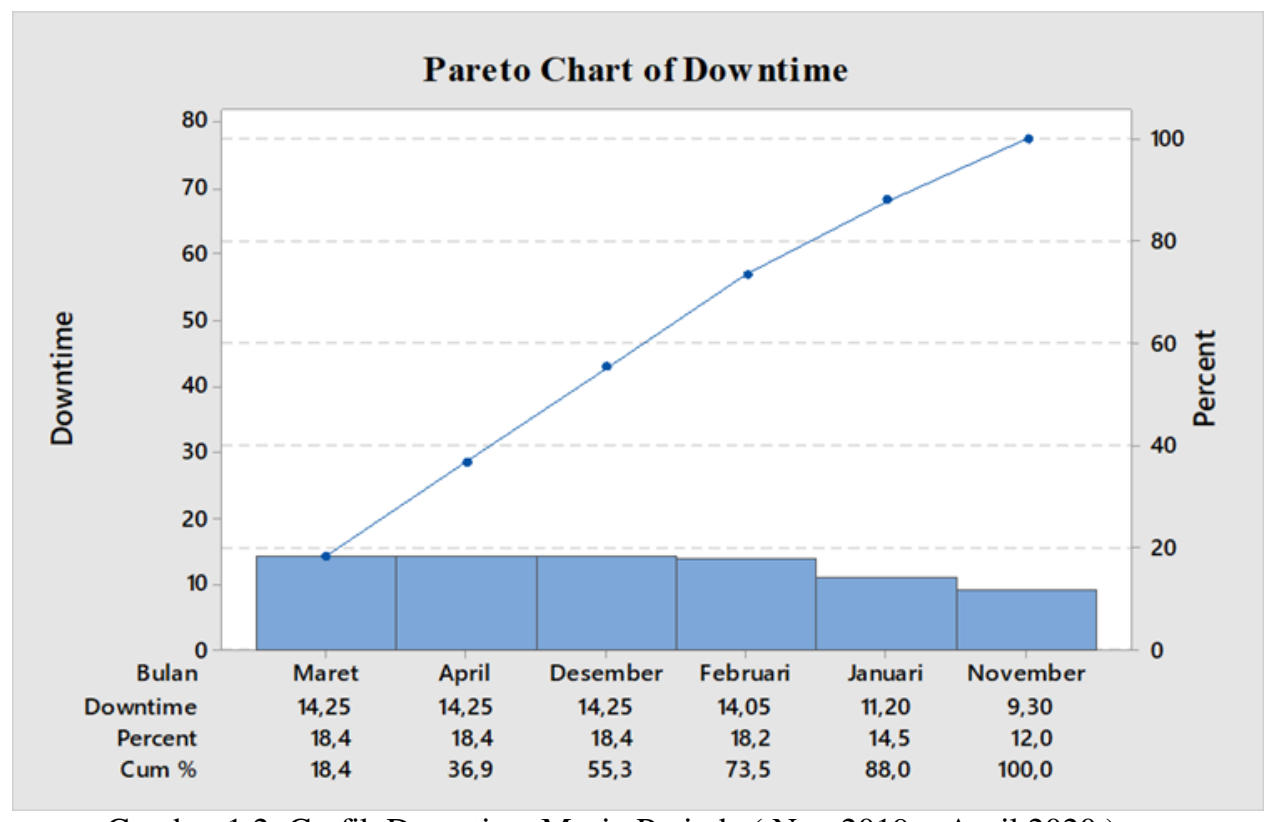

Gambar 1.2. Grafik Downtime Mesin Periode ( Nov 2019 - April 2020 )

\section{LANDASAN TEORI}

\subsection{Mesin Welding MIG}

Pengelasan menggunakan welding MIG menurut Ausaid (2001) yaitu menggunakan gas nyala yang dihasilkan oleh busur nyala listrik, dipakai sebagai pencair metal yang dilas dan metal penambah disebut juga dengan Solid Wire. Sebagai pelindung oksidasi dipakai gas pelindung berupa gas kekal (inert), $\mathrm{CO}_{2}$ dan Arcal 21. Dan juga Wire Feeder berfungsi memutar elektroda menjulur keluar pada saat proses pengelasan berlangsung.
Komponen Utama Las MIG menurut Eka Yogaswara (2004) adalah Peralatan yang berhubungan langsung dengan proses pengelasan tersebut, yaitu terdiri :
1. Mesin Trafo
2. Wire Feeder
3. Welding Gun
4. Regulator
5. Kabel Las atau Saklar Kontrol

\subsection{Perawatan ( Maintenance )}

Perawatan menurut Ebeling (1997) dalam jurnal Rio (2013) adalah probabilitas bahwa suatu komponen atau sistem yang rusak akan diperbaiki dalam 
suatu jangka waktu tertentu, dimana perawatan dilakukan sesuai dengan prosedur yang seharusnya.

\subsubsection{Jenis Perawatan}

Terdapat 2 jenis tindakan utama pada perawatan ;

1. Pemeliharaan Pencegahan (Preventive Maintenance)

Pemeliharaan pencegahan dilakukan guna memperpanjang umur sistem atau meningkatkan kehandalan dari sistem tersebut.

2. Pemeliharaan Perbaikan (Corrective Maintenance)

Pemeliharaan yang terdiri dari tindakan mengembalikan kondisi sistem atau produk yang rusak atau gagal beroperasi kembali ke kondisi beroperasi.

\subsubsection{Metode Penjadwalan Perawatan}

Sistem penjadwalan yang baik akan menunjang kelancaran dalam penyelesaian suatu pekerjaan. Karena itu jadwal harus dibuat oleh orang yang cermat dalam mempertimbangkan segala sesuatunya yang berkaitan, karena tugasnya adalah menyiapkan susunan pekerjaan, menetapkan waktu dan saat penyelesaian, membuat rencana kerja dan sebagainya.

\subsection{Performance Maintenance}

Performance Maintenance terdiri dari 3 bagian, menurut Kostas N.D (1981:73) yaitu:

a. Reliability adalah kemungkinan (probabilitas) dimana peralatan dapat beroperasi dibawah keadaan normal dengan baik. Mean Time Between Failure (MTBF) adalah rata-rata waktu suatu mesin dapat dioperasikan sebelum terjadinya kerusakan.

$M T B F=\frac{\text { Total Operational Time }}{\text { Frekuaensi Breakdown }}$

b. Maintainability adalah suatu usaha dan biaya untuk melakukan perawatan. Suatu prngukuran dari Maintainability adalah Mean Time To Repair (MTTR). Tingginya MTTR mengindikasi rendahnya maintainability.

$$
M T T R=\frac{\text { Breakdown Time }}{\text { Frekuensi Breakdown }}
$$

c. Availability adalah proporsi dari waktu peralatan atau mesin yang sebenarnya tersedia untuk melakukan suatu pekerjaan dengan waktu yang ditargetkan seharusnya tersedia untuk melakukan suatu pekerjaan.

$$
\text { Availability }=\frac{\text { Tot.Operational Time }}{\text { Loading Time }} \times 100 \%
$$

\subsection{Reliability Centered Maintenance (RCM) \\ Metode Reliability Centered} Maintenance (RCM) menurut John Moubray (1997) dalam jurnal Rio (2013) adalah metode pemeliharaan yang menentukan langkah-langkah yang harus diambil untuk menjamin peralatan bekerja sesuai dengan fungsinya. Metoda $R C M$ meliputi pembuatan kegagalan fungsi yang kemudian akan dicari mode kerusakannya.

\subsubsection{Akibat Kerusakan Menurut RCM}

Kegagalan fungsi didefinisikan sebagai ketidakmampuan untuk memenuhi fungsi, poin pertama adalah kegagalan untuk memenuhi fungsi primer. Poin kedua adalah kegagalan untuk fungsi sekunder. Selain dari kedua kegagalan tersebut juga ada yang dinamakan kegagalan tersembunyi. Kegagalan tersembunyi adalah kegagalan yang dalam kondisi kerja normal tidak tampak.

Akibat kerusakan menurut Reliability Centered Maintenance dapat dikelompokkan menjadi empat bagian:
a. Akibat terhadap kerusakan tersembunyi.
b. Akibat terhadap keselamatan operator dan lingkungan kerja
c. Akibat terhadap proses produksi
d. Akibat terhadap non produksi 


\subsubsection{Karakteristik RCM}

Karakteristik RCM yaitu:

1. Menjaga fungsi sistem peralatan, bukan hanya menjaga peralatan agar tetap bekerja.

2. Mengetahui fungsi sistem berarti mengetahui keluaran yang menjadi tujuan sistem dan dengan demikian dapat direncanakan tindakan perawatan untuk menjaga keluaran sistem sesuai dengan unjuk kerja yang dimiliki peralatan.

3. Mengidentifikasi mode kerusakan spesifik dalam bagian-bagian peralatan yang potensial menghasilkan kerusakan fungsi sistem.

Membuat prioritas perawatan dari mode kerusakan yang terjadi. Prioritas ini berdasarkan mode kerusakan yang memberikan kontribusi terbesar dalam sistem akan mendapat prioritas tertinggi.

\subsection{Failure Mode ande Effect Analysis} (FMEA)

Menurut Bangun (2014) Failure

Mode and Effect Analysis adalah metode yang digunakan untuk mengidentifikasi bentuk kegagalan yang mungkin menyebabkan setiap kegagalan fungsi dan untuk memastikan pengaruh kegagalan berhubungan dengan setiap bentuk gagasan. Untuk mengidentifikasi penyebab kegagalan tertinggi pada setiap kegagalan yang terjadi pada komponen, maka dilakukan analisa dengan menggunakan metode FMEA dengan beberapa tahapan yaitu:

a. Identifikasi Kegagalan (Failure)

b. Identifikasi Fungsi Kegagalan Mesin (Function Failure)

c. Identifikasi Penyebab Kegagalan (Failure Mode)

d. Identifikasi efek dari kegagalan (Failure Effect)

e. Perhitungan Severity $(S)$

$f$. Perhitungan Occurance $(O)$

g. Perhitungan Detection $(D)$ h. Perhitungan Risk Priority Number (RPN)

$R P N=S x O x D$

Nilai RPN menunjukan keseriusan dari potensi kegagalan, semakin tinggi nilai RPN maka menunjukan semakin bermasalah.

\subsection{Distribusi Normal}

Distribusi normal mungkin merupakan distribusi probabilitas yang paling penting baik dalam teori maupun aplikasi statistik. Distribusi ini digunakan jika pengaruh suatu kerandoman diakibatkan oleh sejumlah variasi random yang tidak bergantungan yang kecil atau sedikit.

Fungsi-fungsi dalam distribusi normal ;

1. Fungsi Kepadatan Kemungkinan ( Probability Density Function )

$f(t)=\frac{1}{\sigma \sqrt{2 \pi}} \exp \left(-\frac{(t-\mu)^{2}}{2 \sigma^{2}}\right)$

$-\infty<\mathrm{t}<\infty$

2. Fungsi Kumulatif Kerusakan ( Cumulative Density Function )

$F(t)=\varnothing\left(\frac{t-\mu}{\sigma}\right)$

$\mu=$ Rata-rata

$\sigma=$ Standar deviasi

$\varnothing=$ Nilai z diperoleh dari tabel distribusi

3. Fungsi Keandalan ( Reliability Function )

$R(t)=1-\emptyset\left(\frac{t-\mu}{\sigma}\right)$

\subsection{Distribusi Lognormal}

Distribusi Lognormal merupakan distribusi yang berguna untuk menggambarkan distribusi kerusakan untuk situasi yang bervariasi. Distribusi lognormal banyak digunakan di bidang teknik.

\subsection{Distribusi Eksponensial}

Menggambarkan suatu kerusakan dari mesin yang disebabkan oleh kerusakan pada salah satu komponen dari mesin atau peralatan yang menyebabkan mesin terhenti. Dalam hal ini kerusakan tidak dipengaruhi oleh unsur pemakaian peralatan. 


\subsection{Distribusi Weibull}

Distribusi Weibull pertama kali diperkenalkan oleh ahli fisika dari Swedia Wallodi Weibull pada tahun 1939. Dalam aplikasinya, distribusi ini sering digunakan untuk memodelkan "waktu sampai kegagalan" (time to failure) dari suatu sistem fisika.

\subsection{Mean Time To Failure (MTTF)}

Menurut Jardine (1937) MTTF adalah nilai yang diharapkan dari suatu distribusi kerusakan dengan didefinisikan oleh Probability Density Function.

$$
M T T F=E(t)=\int_{0}^{\infty} t f(t) d t
$$

Perhitungan nilai MTTF untuk distribusi normal :

$$
M T T F=\mu
$$

\subsection{Availability}

Menurut Ansori (2013) availabilitas merupakan suatu rasio yang menggambarkan pemanfaatan waktu yang tersedia untuk kegiatan operasi mesin atau komponen. Formula yang digunakan untuk mengukur availabilitas adalah:

$$
A v=\frac{M T T F}{M T T F+M T T R} \times 100 \%
$$

\section{METODE PENELITIAN}

\subsection{Jenis Penelitian}

Jenis penelitian kualitatif adalah merupakan penelitian yang dilakukan dengan menggunakan riset yang mempunyai sifat deskriptif dan lebih cenderung menggunakan analisis. Proses serta makna lebih cenderung didalam penelitian kualitatif, landasan dari sebuah teori dimanfaatkan untuk pemandu agar fokus dari penelitian sesuai dengan fakta yang ada di lapangan.

\subsection{Teknik Pengumpulan Data}

Dalam melakukan pengumpulan data untuk dianalisis, penulis melakukan beberapa cara. Diantaranya :

\section{Observasi lapangan}

Dengan cara ini penulis mencari data dengan meninjau langsung ke lapangan, melihat apa yang terjadi di area produksi, pada proses perbaikan mesin welding berikut data-data yang dikumpulkan:

a. Data waktu pengamatan data waktu kerja masing-masing karyawan yang diambil melalui proses observasi dengan pihak perusahaan dan karyawan.

$b$. Data mengenai jumlah mesin welding yang digunakan.

c. Data mengenai waktu dan hasil kerusakan mesin, meliputi tanggal terjadinya kerusakan, waktu mulai dan selesai perawatan.

\section{Wawancara}

Penulis melakukan wawancara secara langsung dengan pembimbing dalam perusahaan tentang proses perbaikan mesin welding yang berhubungan permasalahan penelitian ini :
a. Waktu kerja masing-masing operator pada departement maintenance dan waktu kerja karyawan produksi.
b. Data hasil kerusakan mesin welding dan data perhitungan Komponen yang paling kritis.

\subsection{Teknik Pengolahan Data}

Setelah melakukan teknik pengumpulan data untuk penelitian, maka tahapan selanjutnya adalah melakukan pengolahan data. di antaranya :

a. Berdasarkan data histori waktu kerja masing-masing operator dan karyawan yang terdapat pada departement maintenance dan produksi.

$b$. Data kerusakan komponen paling kritis dan hasil analisa tersebut akan di hitung dengan uji Penentuan distribusi data, perhitungan Time To Failure (TTF) untuk mengetahui selisih waktu komponen diperbaiki dengan waktu kerusakan berikutnya dan perhitungan probabilitas dari mesin (Availability).

c. Melakukan perhitungan Failure Mode and Effect Analysis (FMEA) untuk mengetahui nilai kerusakan komponen yang kritis. 
d. Menggunakan Software Minitab 18 untuk melakukan banyak perhitungan seperti Penentuan Distribusi, Perhitungan MLE, MTTF, Interval Perawatan dan Availability.

\subsection{Proses Penelitian}

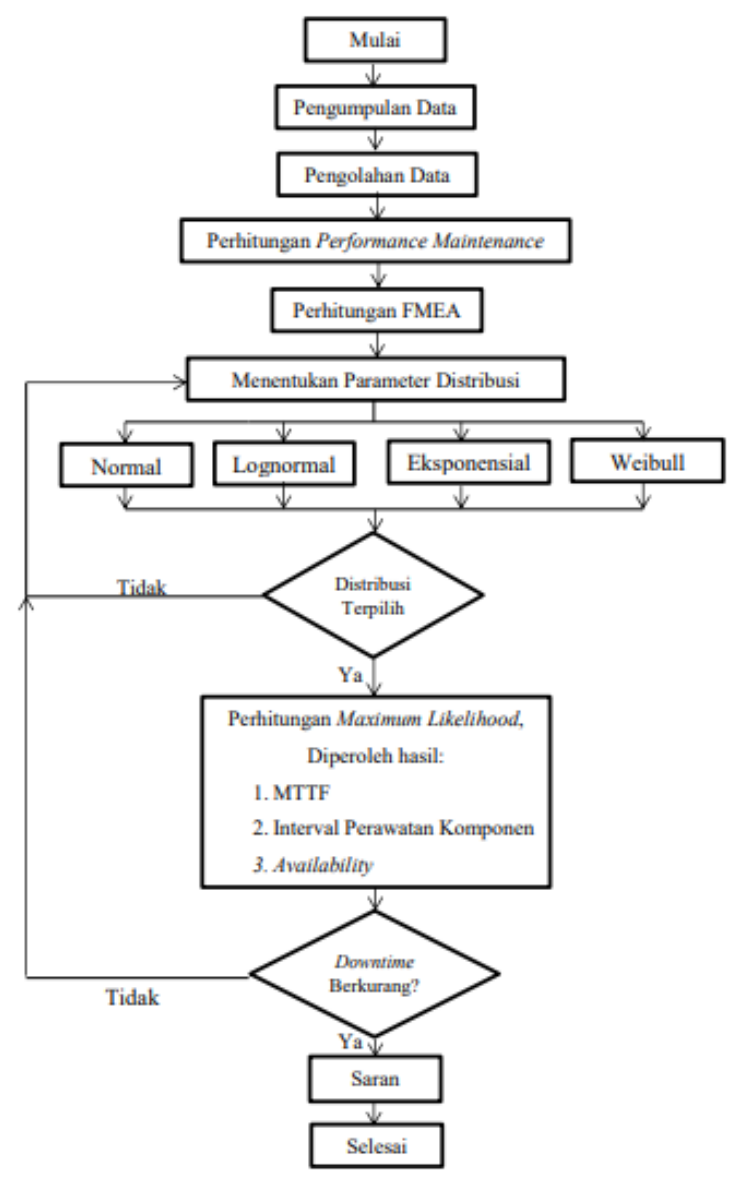

Gambar 3.1. Diagram alir proses penelitian

\section{ANALISA}

\subsection{Performance Maintenance}

Dari data kerusakan pada tabel 1.1, MTBF dan MTTR dapat dihitung menggunakan persamaan (2.1), (2.2) dan (2.3) ;

Performance Maintenance bulan November 2019

$M T B F=\frac{380.30}{7}=54.33 \mathrm{jam}$

$\operatorname{MTTR}=\frac{9.30}{7}=1.33 \mathrm{jam}$

Availability $=\frac{380.30}{390} \times 100 \%=97.51 \%$

Maka diperoleh :

Tabel 4.1. Rekapitulasi Performance Maintenance

\begin{tabular}{lccc}
\hline Bulan & $\begin{array}{c}\text { MTBF } \\
\text { (Jam) }\end{array}$ & $\begin{array}{c}\text { MTTR } \\
\text { (Jam) }\end{array}$ & $\begin{array}{c}\text { Availabilit } \\
\mathbf{y}(\%)\end{array}$ \\
\hline November & 54.33 & 1.33 & 97.51 \\
\hline Desember & 46.28 & 1.19 & 97.42 \\
\hline Januari & 72.09 & 1.24 & 98.24 \\
\hline Februari & 55.56 & 1.41 & 97.46 \\
\hline Maret & 68.37 & 1.58 & 97.67 \\
\hline April & 31.92 & 1.78 & 94.67 \\
\hline
\end{tabular}

\subsection{Failure Mode and Effect Analysis (FMEA)}

Dalam perhitungan ini menggunakan nilai rating yang mana menggambarkan kerusakan yang terjadi pada mesin dan komponen saat proses produksi. Berikut ini nilai rating yang digunakan untuk menghitung total Risk Priority Number (RPN) diantaranya yaitu severity, occurance, dan detection.

Tabel 4.2. Kriteria dan Nilai Ranking Severity

\begin{tabular}{ccc}
\hline \multicolumn{1}{c}{ Efek } & Severity & Ranking \\
\hline Proses produksi berhenti. & $\begin{array}{c}\text { Tidak tersedianya komponen } \\
\text { pengganti. }\end{array}$ & $\mathbf{1 0}$ \\
\hline $\begin{array}{c}\text { Proses produksi berjalan } \\
\text { dengan sangat lambat. }\end{array}$ & $\begin{array}{c}\text { Tidak tersedianya komponen } \\
\text { pengganti. }\end{array}$ & $\mathbf{9}$ \\
\hline $\begin{array}{c}\text { Proses produksi berjalan } \\
\text { dengan lambat. }\end{array}$ & Komponen pengganti tersedia & $\mathbf{8}$ \\
\hline $\begin{array}{c}\text { Proses produksi berjalan } \\
\text { dengan sedikit terhambat. }\end{array}$ & Komponen tersedia. & $\mathbf{7}$ \\
\hline
\end{tabular}




\begin{tabular}{ccc}
\hline $\begin{array}{c}\text { Proses produksi berjalan } \\
\text { cukup lancar. }\end{array}$ & Mesin rusak cukup parah. & $\mathbf{6}$ \\
\hline $\begin{array}{c}\text { Proses produksi berjalan } \\
\text { lancar. }\end{array}$ & Rusak pada settingan mesin. & $\mathbf{5}$ \\
\hline $\begin{array}{c}\text { Proses produksi berjalan } \\
\text { dengan bantuan operator. }\end{array}$ & Mesin rusak ringan. & $\mathbf{4}$ \\
\hline $\begin{array}{c}\text { Proses produksi sedikit } \\
\text { terganggu. }\end{array}$ & Menunggu Komponen \\
pengganti. & $\mathbf{3}$ \\
\hline $\begin{array}{c}\text { Proses produksi tetap } \\
\text { berjalan. }\end{array}$ & Mesin error. \\
\hline $\begin{array}{c}\text { Proses produksi tidak } \\
\text { terganggu. }\end{array}$ & Mesin kotor. \\
\hline
\end{tabular}

Tabel 4.3. Kriteria dan Nilai Ranking Occurance

\begin{tabular}{|c|c|c|}
\hline Probability Of Failure & Failure Rates & Ranking \\
\hline Sangat tinggi. & Setiap hari rusak & $\mathbf{1 0}$ \\
\hline $\begin{array}{c}\text { Kerusakan hampir tidak } \\
\text { dihindari }\end{array}$ & Setiap 2 hari rusak & 9 \\
\hline Tinggi & Setiap 3 hari rusak & 8 \\
\hline Kerusakan sering terjadi. & Setiap 4 hari rusak & 7 \\
\hline $\begin{array}{c}\text { Kerusakan terulang kali } \\
\text { terjadi. }\end{array}$ & Setiap 5 hari rusak. & 6 \\
\hline Sedang. & Setiap 6 hari rusak & 5 \\
\hline Kerusakan sesekali terjadi. & $\begin{array}{c}\text { Setiap minggu sekali } \\
\text { rusak. }\end{array}$ & 4 \\
\hline Kerusakan jarang terjadi. & Setiap 2 minggu sekali. & 3 \\
\hline Rendah. & Setiap 3 minggu sekali & 2 \\
\hline $\begin{array}{l}\text { Relatif sedikit } \\
\text { kerusakannya. }\end{array}$ & Setiap sebulan sekali. & 1 \\
\hline
\end{tabular}

Tabel 4.4. Kriteria dan Nilai Ranking Detection

\begin{tabular}{llc}
\multicolumn{1}{c}{ Deteksi } & \multicolumn{1}{c}{ Criteria Likelibood of Detection } & Ranking \\
\hline Sepenuhnya tidak pasti. & Alat atau informasi tidak mendeteksi kerusakan. & $\mathbf{1 0}$ \\
\hline Sangat jarang. & Alat untuk mendeteksi kerusakan rusak. & $\mathbf{9}$ \\
\hline Jarang. & Jarang alat untuk mendeteksi penyebab & $\mathbf{8}$ \\
& kerusakan. & $\mathbf{7}$ \\
\hline Sangat rendah. & Kemampuan alat untuk mendeteksi kerusakan & $\mathbf{6}$ \\
\hline Rendah. & sangat rendah. & Alat untuk mendeteksi kerusakan rendah. \\
\hline
\end{tabular}




\begin{tabular}{llc}
\hline Cukup. & Alat cukup untuk mendeteksi kerusakan. & $\mathbf{5}$ \\
\hline Cukup tinggi. & $\begin{array}{l}\text { Alat atau informasi cukup tinggi mendeteksi } \\
\text { penyebab kerusakan. }\end{array}$ & $\mathbf{4}$ \\
\hline Tinggi. & $\begin{array}{l}\text { Alat atau informasi tinggi kemungkinan untuk } \\
\text { mendeteksi penyebab kerusakan. }\end{array}$ & $\mathbf{3}$ \\
\hline Sangat tinggi. & $\begin{array}{l}\text { Alat atau informasi sangat tinggi dapat } \\
\text { mendeteksi penyebab kerusakan. }\end{array}$ & $\mathbf{2}$ \\
\hline Hampir pasti. & $\begin{array}{l}\text { Operator Produksi dalam memberikan laporan } \\
\text { kerusakan sama dengan apa yang terjadi di lapangan }\end{array}$ & $\mathbf{1}$ \\
\hline
\end{tabular}

Berdasarkan analisis melalui FMEA maka nilai Risk Priority Number (RPN) untuk komponen yang didapatkan dari penentuan nilai rating severity, occurance, dan detection. Menggunakan persamaan (2.4) nilai RPN diperoleh :

$\mathrm{S}=$ severity dengan nilai rangking 1-10

$\mathrm{O}=$ occurance dengan nilai rangking 1-10

$\mathrm{D}=$ detection dengan nilai rangking 1-10

Tabel 4.5. FMEA pada Komponen Wire Feeder

\begin{tabular}{|c|c|c|c|c|c|c|c|c|}
\hline \multicolumn{2}{|c|}{ FMEA Worksheet } & \multicolumn{7}{|c|}{ SISTEM : Komponen wire feeder } \\
\hline Function & $\begin{array}{c}\text { Potential } \\
\text { Failure } \\
\text { Mode }\end{array}$ & $\begin{array}{c}\text { Potential } \\
\text { Effect } \\
\text { Failure }\end{array}$ & $S$ & $\begin{array}{c}\text { Potential } \\
\text { Effect } \\
\text { Failure }\end{array}$ & $O$ & $\begin{array}{c}\text { Potential } \\
\text { Effect } \\
\text { Failure }\end{array}$ & $D$ & RPN \\
\hline \multirow{3}{*}{$\begin{array}{l}\text { Pengontrol } \\
\text { Kawat } \\
\text { elektroda }\end{array}$} & $\begin{array}{l}\text { Pengumpan } \\
\text { Kawat rusak. }\end{array}$ & $\begin{array}{l}\text { Daya putar } \\
\text { stang metal } \\
\text { tidak } \\
\text { beraturan }\end{array}$ & 9 & $\begin{array}{l}\text { Bagian } \\
\text { komponen } \\
\text { stang } \\
\text { metal tidak } \\
\text { bekerja }\end{array}$ & 8 & $\begin{array}{l}\text { Mengontrol } \\
\text { kinerja stang } \\
\text { metal jalan }\end{array}$ & 8 & 576 \\
\hline & $\begin{array}{l}\text { Wire feeder } \\
\text { tidak bekerja }\end{array}$ & $\begin{array}{l}\text { Kawat } \\
\text { elektroda } \\
\text { habis }\end{array}$ & 7 & $\begin{array}{l}\text { Fly wheel } \\
\text { berhenti }\end{array}$ & 1 & $\begin{array}{l}\text { Mengganti } \\
\text { komponen }\end{array}$ & 5 & 35 \\
\hline & & & & & & & Total & 611 \\
\hline
\end{tabular}

\subsection{Distribusi Data}

Penentuan distribusi waktu antar kerusakan dan waktu antar perbaikan dilakukan dengan software Minitab 18. Pemilihan distribusi dilakukan berdasarkan nilai correlation coefficient yang terbesar dari setiap distribusi.
Tabel 4.6. Hasil Distribution ID Plot

\begin{tabular}{lrr}
\multicolumn{3}{c}{ Codness-of-Fit } \\
& $\begin{array}{r}\text { Anderson-Darling } \\
(\text { adj })\end{array}$ & $\begin{array}{r}\text { Correlation } \\
\text { Coefficient }\end{array}$ \\
\hline Distribution & 1,878 & 0,932 \\
\hline Weibull & 2,920 & 0,867 \\
Lognormal & 2,035 & $*$ \\
Exponential & 1,124 & 0,958 \\
\hline
\end{tabular}


Tabel 4.7. Distribusi Index of Fit data TTF

\begin{tabular}{ccc}
\hline \multirow{2}{*}{ Komponen } & Distribusi & Index Of Fit \\
\cline { 2 - 3 } Wire feeder & Weibul & 0.932 \\
\cline { 2 - 3 } & Lognormal & 0.867 \\
\cline { 2 - 3 } & Exponential & Ditolak \\
\cline { 2 - 3 } & Normal & 0.958 \\
\hline
\end{tabular}

Setelah dilakukan perhitungan dapat dilihat hasil dimana Index Of Fit yang terbesar adalah 0.958 yaitu distribusi normal. Maka dapat disimpulkan bahwa data selang waktu antar kerusakan komponen wire feeder adalah berdistribusi normal.

Selanjutnya adalah hasil perhitungan parameter berdasarkan pada distribusi yang terpilih menggunakan bantuan software minitab 18 dengan metode Maximum Likelihood Estimator (MLE).

secara manual dengan bantuan software,

Distribution Analysis: komponen wire feeder (TTF)

Variable: komponen wire feeder (TTF)

Censoring

Censoring Information Count

Uncensored value 23

Estimation Method: Maximum Likelihood

Distribution: Normal

Parameter Estimates

\begin{tabular}{|c|c|c|c|c|}
\hline \multirow[b]{2}{*}{ Parameter } & \multicolumn{2}{|r|}{ Standard } & \multicolumn{2}{|c|}{$95,0 \%$ NormalCI } \\
\hline & Estimate & Error & Lower & Upper \\
\hline Mean & 61,9391 & 10,1349 & 42,0751 & 81,8032 \\
\hline StDev & 48,6053 & 7,16645 & 36,4066 & 64,8912 \\
\hline \multicolumn{5}{|c|}{ Log-Likelihood = -121,961 } \\
\hline \multicolumn{5}{|c|}{ Goodness-of-Fit } \\
\hline \multicolumn{5}{|c|}{ Anderson-Darling } \\
\hline \multicolumn{5}{|c|}{ (Adjusted) } \\
\hline & 1,150 & & & \\
\hline
\end{tabular}

Gambar 4.1. Hasil MLE Analysis

Tabel 4.8. Hasil MLE Characteristics

\begin{tabular}{|lrrrr|}
\hline & & \multicolumn{3}{c|}{$\mathbf{9 5 , 0 \%}$ Normal CI } \\
& Estimate & $\begin{array}{r}\text { Standard } \\
\text { Error }\end{array}$ & Lower & Upper \\
\hline Mean(MTTF) & 61,9391 & 10,1349 & 42,0751 & 81,8032 \\
Standard Deviation & 48,6053 & 7,16645 & 36,4066 & 64,8912 \\
Median & 61,9391 & 10,1349 & 42,0751 & 81,8032 \\
First Quartile(Q1) & 29,1554 & 11,2286 & 7,14780 & 51,1630 \\
Third Quartile(Q3) & 94,7229 & 11,2286 & 72,7153 & 116,730 \\
Interquartile Range(IQR) & $\mathbf{6 5 , 5 6 7 5}$ & $\mathbf{9 , 6 6 7 4 0}$ & 49,1118 & 87,5369 \\
\hline
\end{tabular}


Tabel 4.9. Hasil MLE data TTF

\begin{tabular}{c|c|c}
\hline Komponen & Distribusi & Parameter \\
\hline \multirow{2}{*}{ Wire feeder } & Normal & $\begin{array}{c}\mu: 61.9391 \\
\alpha: 48.6053\end{array}$ \\
\hline
\end{tabular}

\subsection{Perhitungan MTTF}

Penentuan Interval Waktu Penggantian Pencegahan Komponen, dan Availability pada komponen Wire feeder

\section{MTTF Komponen Wire feeder}

Setelah didapat distribusi yang sesuai, maka selanjutnya adalah dilakukan perhitungan MTTF berdasarkan parameter distribusi yang terpilih.
Tabel 4.10. Hasil MTTF

\begin{tabular}{ccc}
\hline Komponen & Distribusi & MTTF (Jam) \\
\hline Wire feeder & Normal & 61.9391 \\
\hline
\end{tabular}

Dari tabel diatas didapat nilai MTTF sebesar 61.9391 jam pada komponen Wire feeder menunjukan bahwa setelah kerusakan terjadi, maka kurang lebih 61.9391 jam kemudian akan terjadi kerusakan lagi.

2. Interval Waktu Penggantian Pencegahan Komponen Wire feeder

Untuk melakukan penggantian pencegahan ini dilakukan perhitungan yang sifatnya trial and error dengan bantuan software minitab 18 sehingga diperoleh nilai downtime menurun.

Tabel 4.11. Interval Waktu Penggantian

\begin{tabular}{|c|c|c|c|c|}
\hline \multirow[b]{2}{*}{ Percent } & \multicolumn{4}{|c|}{ Table of Percentiles } \\
\hline & \multicolumn{2}{|r|}{$\begin{array}{l}\text { Standard } \\
\text { Error }\end{array}$} & Lower & Upper \\
\hline 1 & $-51,1336$ & 19,5105 & $-89,3735$ & $-12,8937$ \\
\hline 2 & $-37,8839$ & 17,8700 & $-72,9085$ & $-2,85921$ \\
\hline 3 & $-29,4773$ & 16,8638 & $-62,5298$ & 3,57522 \\
\hline 4 & $-23,1534$ & 16,1283 & $-54,7644$ & 8,45757 \\
\hline 5 & $-18,0094$ & 15,5457 & $-48,4783$ & 12,4595 \\
\hline 6 & $-13,6310$ & 15,0620 & $-43,1521$ & 15,8900 \\
\hline 7 & $-9,79206$ & 14,6483 & $-38,5021$ & 18,9180 \\
\hline 8 & $-6,35473$ & 14,2867 & $-34,3561$ & 21,6466 \\
\hline 9 & $-3,22860$ & 13,9656 & $-30,6007$ & 24,1435 \\
\hline 10 & $-0,351005$ & 13,6772 & $-27,1578$ & 26,4558 \\
\hline 20 & 21,0319 & 11,7938 & $-2,08356$ & 44,1474 \\
\hline 30 & 36,4505 & 10,8092 & 15,2648 & 57,6362 \\
\hline 40 & 49,6251 & 10,2962 & 29,4449 & 69,8054 \\
\hline 50 & 61,9391 & 10,1349 & 42,0751 & 81,8032 \\
\hline 60 & 74,2531 & 10,2962 & 54,0729 & 94,4334 \\
\hline 70 & 87,4277 & 10,8092 & 66,2421 & 108,613 \\
\hline 80 & 102,846 & 11,7938 & 79,7309 & 125,962 \\
\hline 90 & 124,229 & 13,6772 & 97,4225 & 151,036 \\
\hline 91 & 127,107 & 13,9656 & 99,7348 & 154,479 \\
\hline 92 & 130,233 & 14,2867 & 102,232 & 158,234 \\
\hline 93 & 133,670 & 14,6483 & 104,960 & 162,380 \\
\hline 94 & 137,509 & 15,0620 & 107,988 & 167,030 \\
\hline 95 & 141,888 & 15,5457 & 111,419 & 172,357 \\
\hline 96 & 147,032 & 16,1283 & 115,421 & 178,643 \\
\hline
\end{tabular}




\begin{tabular}{lllll}
97 & 153,356 & 16,8638 & 120,303 & 186,408 \\
98 & 161,762 & 17,8700 & 126,737 & 196,787 \\
99 & 175,012 & 19,5105 & 136,772 & 213,252 \\
\hline
\end{tabular}

3. Analisis Perhitungan Availability Komponen

Wire feeder

Availability merupakan probabilitas suatu komponen dapat beroperasi sesuai fungsinya, semakin tinggi kemampuan komponen maka semakin baik keadaan komponen tersebut untuk dapat beroperasi dengan baik, menggunakan persamaan (2.10) diperoleh Availability $=98,01 \%$, artinya bahwa setelah dilakukan tindakan perawatan pencegahan terhadap komponen maka kerusakan pada komponen tersebut dapat teratasi sebesar $98 \%$ dari total kerusakan komponen Wire feeder

\section{'5. Kesimpulan}

Berdasarkan hasil pengolahan data dan analisa yang telah dibahas pada bab sebelumnya dapat diambil kesimpulan sebagai berikut:

1. Hasil perhitungan berdasarkan FMEA diperoleh ;

a. Nilai RPN pada komponen kritis wire feeder yaitu sebesar 611 .

b. Distribusi waktu antara kerusakan komponen wire feeder adalah distribusi normal.

c. Nilai parameter untuk komponen wire feeder pada median adalah 61.9391, dan standar deviasi yaitu 48.6053.

d. Nilai MTTF untuk komponen wire feeder adalah 61.9391 jam.

e. Selang waktu interval penggantian pencegahan dan perawatan pada komponen wire feeder adalah sebesar 10.1349

2. Berdasarkan perhitungan performance maintenance periode Nov 2019 April 2020 ;

a. $\mathrm{MTBF}=31,92 \sim 72,09 \mathrm{jam}$.

b. $\mathrm{MTTR}=1,19 \sim 1,78 \mathrm{jam}$.

c. Availability $=94,67 \% \sim 98,24 \%$.

3. Nilai Availability untuk komponen wire feeder adalah $98 \%$.

\section{DAFTAR PUSTAKA}

Al-Ghamdi, dkk, (2005), "Reliability Centered Maintenance Concepts and Applications: A Case Study" Univ. Cincinnati Industrial Engineering, International Journal Of Industrial Engineering-Theory Applications And Practice; Pp: 123-132.

Destina Surya Dhamayanti, dkk, (2016)," Usulan Preventive Maintenance Pada Mesin Komori LS440 Dengan Menggunakan Metode Reliability Centered Maintenance (RCM II) Dan Risk Based Maintenance (RBM) Di PT ABC', Jurnal Rekayasa Sistem \& Industri, Vol. 3 No. 2, Telkom University.

Ully Tri Kirana, dkk, (2016), "Perencanaan Kebijakan

Perawatan Mesin Corazza FF100 Pada Line 3 PT XYZ Dengan Metode Reliability Centered Maintenance (RCM) II', Jurnal Rekayasa Sistem \& Industri, Vol. 3, No.1, Universitas Telkom.

Noor Ahmadi, Nur Yulianti Hidayah, (2017)," Analisis Pemeliharaan Mesin Blowmould Dengan Metode RCM Di PT. CCAI', Jurnal Optimasi Sistem Industri, Vol.16 No. 2, Universitas Pancasila.

Mohammad Tahril Azis, dkk, (2010),"

Penerapan Metode Reliability

Centered Maintenance (RCM)

Berbasis Web Pada Sistem

Pendingin Primer Di Reaktor

Serba Guna GA. Siwabessy", JFN, Vol.4 No.1, UGM.

M. Rusydi Alwi, (2016)," Reliability Centered Maintenance Dalam Perawatan F.O. Service Pump Sistem Bahan Bakar Kapal Ikan", 
JRTK, Vol.14 No.1, Universitas Hasanuddin.

Hamim Rachman, dkk, (2017)," Usulan Perawatan Sistem Boiler dengan Metode Reliability Centered Maintenance (RCM)", Jurnal Tenik Industri, Vol.18 No.1, UMM Malang.

Agustinus Dwi Susanto, Hery Hamdi Azwir, (2018)," Perencanaan Perawatan Pada Unit Kompresor
Tipe Screw Dengan Metode RCM di Industri Otomotif', Jurnal Ilmiah Teknik Industri, ISSN 2480-4038, President University.

Wirda Hamro Afiva, dkk, (2019)," Penerapan Metode Reliability Centered Maintenance (RCM) pada Perencanaan Interval Preventive Maintenance dan Estimasi Biaya Pemeliharaan Menggunakan Analisis FMECA", Jurnal PASTI, Vol.XIII No.3, Universitas Telko 